Pesq. Vet. Bras. 28(3):140-148, março 2008

\title{
Aspectos virológicos e clínico-patológicos da infecção genital aguda e latente pelo herpesvírus bovino tipo 1.2 em bezerras infectadas experimentalmente ${ }^{1}$
}

\author{
Andréia Henzel², Diego G. Diel ${ }^{2}$, Sandra Arenhart², Fernanda S. Flores \\ Vogel $^{2}$, Rudi Weiblen ${ }^{2}$ e Eduardo F. Flores ${ }^{2 *}$
}

\begin{abstract}
Henzel A., Diel D.G., Arenhart S., Vogel F.S.F., Weiblen R. \& Flores E.F. 2008. [Virological and clinico-pathological features of acute vulvovaginitis and latent infection by bovine herpesvirus $\mathbf{1 . 2}$ in heifers experimentally infected.] Aspectos virológicos e clínico-patológicos da infecção genital aguda e latente pelo herpesvírus bovino tipo $1.2 \mathrm{em}$ bezerras experimentalmente infectadas. Pesquisa Veterinária Brasileira 28(3):140-148. Departamento de Medicina Veterinária Preventiva, Universidade Federal de Santa Maria, 97105-900 Santa Maria, RS, Brazil. E-mail: flores@ccr.ufsm.br

Venereal infection of heifers and cows with bovine herpesvirus type 1.2 (BoHV-1.2) may result in vulvovaginitis and transient infertility. The acute infection is followed by the establishment of latent infection which can be periodically reactivated. We herein describe the virology and clinico-pathological aspects of acute and recrudescent vulvovaginitis in heifers inoculated with a Brazilian BoHV-1.2 isolate recovered from an outbreak of balanoposthitis. Genital inoculation of isolate SV-56/90 (10 ${ }^{8.1}$ TCID $_{50} /$ animal) in four eight-months-old heifers resulted in efficient virus replication in the genital mucosa and the development of moderate to severe vulvovaginitis. The inoculated heifers shed virus in genital secretions in titers up to $10^{7.3} \mathrm{TCID}_{50} / \mathrm{mL}$ until day 10 pi and developed genital congestion, swelling, vesicles and pustules. The vesicles and pustules increased in size eventually coalesced and became covered with a yellowish exsudate. These signs appeared at day $2 \mathrm{pi}$, increased in severity up to days 5 - 8 pi and progressively subsided thereafter. Dexamethasone administration at day 55 pi resulted in virus shedding in vaginal secretions for up to 10 days. Virus reactivation in all animals was accompanied by clinical recrudescence of the disease, yet less severe than during acute infection. Examination of sacral ganglia and lymph nodes by PCR at day 36 postreactivation revealed the presence of latent viral DNA in the pudendal (4/4), genitofemoral, sciatic and rectal caudal (3/4) and obturator nerve ganglia (1/4); in addition to several regional lymph nodes. These results demonstrate the virulence of isolate SV$56 / 90$ for heifers and pave the way for its use in further pathogenesis studies and vaccine-challenge trials.
\end{abstract}

INDEX TERMS: Bovine herpesvirus, BoHV-1.2, vulvovaginitis, genital infection, latency, reactivation.

\footnotetext{
${ }^{1}$ Recebido em 3 de dezembro de 2007.

Aceito para publicação em 4 de dezembro de 2007.

2 Departamento de Medicina Veterinária Preventiva, Universidade Federal de Santa Maria (UFSM), Campus de Camobi, Santa Maria, RS 97105-900, Brazil. *Autor para correspondência: flores@ccr.ufsm.br
}

RESUMO.- A infecção genital de vacas pelo herpesvírus bovino tipo 1.2 (BoHV-1.2) pode resultar em vulvovaginite e infertilidade temporária. Após a infecção aguda, o BoHV1 estabelece infecção latente, que pode cursar com episódios periódicos de reativação. O presente trabalho des- 
creve os aspectos virológicos e clínico-patológicos da vulvovaginite aguda e infecção latente resultantes da inoculação de bezerras com uma amostra de BoHV-1.2 isolada de casos de balanopostite em touros. A inoculação do vírus em quatro bezerras pela via genital ( $10^{8.1} \mathrm{TCID}_{50}$ /animal) resultou em replicação viral na mucosa genital e no desenvolvimento de vulvovaginite moderada a severa. Os animais inoculados excretaram o vírus nas secreções genitais até o dia 10 pós-inoculação (p.i.) com título máximo de $10^{7.3} \mathrm{TCID}_{50} / \mathrm{mL}$. Foram observados congestão e edema da mucosa vulvovestibular, e formação de pequenas vesículas e pústulas. Durante a progressão clínica, as vesículas e pústulas aumentaram de tamanho e eventualmente se tornaram coalescentes e recobertas por um exsudato fino de coloração amarelada. Estes sinais foram observados a partir do dia 2 p.i. e aumentaram progressivamente de severidade até os dias 5-8 p.i. A administração de dexametasona no dia 55 p.i. resultou em excreção viral nas secreções genitais dos quatro animais por até 10 dias. A reativação da infecção latente foi acompanhada de recrudescência clínica, porém com sinais menos severos e com menor duração do que na infecção aguda. O DNA viral latente foi detectado por PCR, aos 36 dias pós-reativação (p.r.), nos seguintes tecidos: gânglio sacrais: pudendo (4/4); genitofemoral e retal caudal (3/4) e obturador (4/4) e em alguns linfonodos regionais. Estes resultados demonstram que o isolado SV-56/90 é virulento para fêmeas soronegativas, após inoculação genital, e pode ser utilizado em estudos de patogenia e de desafio vacinal.

TERMOS DE INDEXAÇÃO: Herpesvírus bovino, BoHV-1.2., vulvovaginite, infecção genital, latência, reativação.

\section{INTRODUÇÃO}

O herpesvírus bovino tipo 1 (BoHV-1) é um vírus DNA de fita dupla, com envelope, membro da família Herpesviridae, subfamília Alphaherpesvirinae e gênero Varicellovirus (Roizman 1992). A infecção pelo BoHV-1 possui distribuição mundial, com exceção de alguns países europeus que recentemente erradicaram a infecção (Van Oirschot 1999). A infecção de bovinos pelo BoHV-1 pode resultar em uma ampla variedade de manifestações clínicas, como doença respiratória (rinotraqueíte infecciosa bovina, IBR), conjuntivite, vulvovaginite (vulvovaginite pustular infecciosa, IPV), balanopostite (balanopostite pustular infecciosa, IPB), infertilidade, abortos e infecção multissistêmica fatal de neonatos (Kahrs 2001). Além disso, após a infecção aguda, o BoHV-1 possui a capacidade de estabelecer infecção latente em gânglios de nervos sensoriais (Homan \& Easterday 1980, Ackermann et al. 1982), o que contribui para a sua perpetuação na natureza (Rock 1994).

Com base em análise de restrição genômica (REA) e na reatividade com anticorpos monoclonais (AcMs), amostras de campo do BoHV-1 foram caracterizadas, e os vírus isolados de doença respiratória foram classificados como BoHV-1.1 e os isolados de infecção genital como
BoHV-1.2 (Metzler et al. 1985, D'Arce et al. 2002). A base molecular do tropismo dos subtipos BoHV-1.1 e do BoHV1.2 pelo trato respiratório e genital, respectivamente, ainda não está esclarecida. Dessa forma, a associação desses vírus com cada síndrome clínica parece não ser mutuamente exclusiva. Assim, bovinos inoculados pela via intranasal com um isolado de BoHV-1.2 desenvolveram doença respiratória leve (Spilki et al. 2004) e bezerras inoculadas pela via vaginal com um isolado de BoHV-1.1 desenvolveram vulvovaginite (Miller \& Van Der Maaten 1984). O contato de bezerros soronegativos com vacas infectadas com um isolado genital de BoHV-1 resultou em doença respiratória e disseminação do vírus entre os bezerros (Smith et al. 1980). Da mesma forma, manifestações respiratórias e genitais concomitantes têm sido descritas em surtos de infecção pelo BoHV-1 (Pritchard et al. 1997).

Os isolados de doença genital podem ser adicionalmente classificados em BoHV-1.2a e 1.2b, com base em reatividade com AcMs e REA. No entanto, a correlação desta classificação com parâmetros epidemiológicos e clínico-patológicos ainda não está bem definida (Van Oirschot 1995). Os isolados de BoHV-1 associados com abortos pertencem principalmente ao subtipo respiratório (BoHV1.1) e menos freqüentemente ao subtipo BoHV-1.2a (Edwards et al. 1991, Miller et al. 1991). Por outro lado, os isolados de BoHV-1.2b aparentemente são menos virulentos e pouco abortigênicos (Whetstone et al. 1989).

O envolvimento do BoHV-1.2 com infecção genital e distúrbios reprodutivos tem sido bem documentado, porém a patogenia da infecção aguda e latente por esse vírus tem sido pouco investigada. Grande parte do conhecimento acerca da infecção provém de estudos antigos, realizados anteriormente à distinção clara dos subtipos 1.1. e 1.2, ou pela inoculação do vírus por vias não naturais (Snowdon 1965, Deas \& Johnston 1973, Allan et al. 1975, Parsonson \& Snowdon 1975, Narita et al. 1978). Assim, conclusões equivocadas ou parcialmente corretas podem ter sido derivadas da inoculação de isolados respiratórios (BoHV-1.1) pela via genital (Narita et al. 1978); pela exposição de fêmeas a touros infectados com isolados não identificados e pouco caracterizados (Allan et al. 1975) e pela investigação do potencial abortigênico dos subtipos 1.1, 1.2a e 1.2b após inoculação intravenosa (Miller et al. 1991).

A habilidade do BoHV-1 persistir no hospedeiro e ser submetido a episódios de reativação após infecção genital tem sido bem demonstrada e foi inicialmente atribuída a uma imunidade de curta duração. Estudos clássicos demonstraram que o vírus persiste no rebanho por meio de episódios periódicos de reativação da infecção latente (Snowdon 1965, Dennet et al. 1976). Após a infecção ou inoculação do BoHV-1.2 no trato genital em fêmeas, o vírus replica na mucosa local e estabelece infecção latente nos gânglios sacrais (Ackermann \& Wyler 1984). Reativação esporádica da infecção latente e conseqüente re-excreção viral podem ocorrer de forma natural ou 
serem induzidas pela administração de corticosteróides (Snowdon 1965, Sheffy \& Davies 1972, Dennet et al. 1976). A reativação da infecção latente pode ser acompanhada de um período de excreção viral sem necessariamente estar acompanhada de sinais clínicos (Snowdon 1965, Dennet et al. 1976). Assim, a infecção latente e posterior reativação explicam a persistência do vírus e o aparecimento de novos casos clínicos no rebanho ao longo do tempo (Dennet et al. 1976, Ackermann et al. 1982, Ackermann \& Wyler 1984, Pritchard et al. 1997). A infecção latente pelo BoHV-1.2 em fêmeas tem sido pouco estudada e vários aspectos da patogenia permanecem não esclarecidos.

Em um estudo anterior, foi relatada a reprodução de balanopostite clínica em touros jovens inoculados pela via intraprepucial com o isolado SV-56/90 (Vogel et al. 2004). O SV-56/90 é uma amostra de BoHV-1.2 isolada de um surto de balanopostite em touros de uma central de inseminação no Rio Grande do Sul, Brasil (Weiblen et al. 1992).

O objetivo do presente estudo foi investigar a habilidade deste isolado em produzir doença genital em bezerras soronegativas após a inoculação genital, além de caracterizar a infecção aguda e latente. A capacidade desse isolado em produzir vulvovaginite clínica pode credenciálo para estudos posteriores de patogenia, como também para uso em testes de desafio e proteção vacinal.

\section{MATERIAL E MÉTODOS}

Desenho experimental. Cinco bezerras soronegativas para o BoHV-1 foram utilizadas neste experimento. Quatro animais foram inoculados com o vírus e um permaneceu como controle. As bezerras foram inoculadas com o BoHV-1.2 pela via genital e a infecção aguda foi monitorada nos aspectos clínicos e virológicos. Cinqüenta e cinco dias após a inoculação (p.i.), os animais foram submetidos à administração de dexametasona (Dx) para reativação da infecção latente, e foram monitoradas nos dias seguintes. Trinta e seis dias após a administração de Dx (p.r.), todos os animais foram submetidos a eutanásia para a coleta de tecidos. Gânglios sacrais e linfonodos regionais foram coletados e submetidos a pesquisa de DNA viral por meio de um PCR-nested.

Vírus e células. Todos os procedimentos de multiplicação e quantificação de vírus, soroneutralização e isolamento viral de secreções vulvovaginais e de tecidos foram realizados em células da linhagem de rim bovino CRIB (Flores \& Donis 1995). As células foram cultivadas em meio essencial mínimo (MEM), contendo penicilina $(1,6 \mathrm{mg} / \mathrm{L})$, estreptomicina $(0,4 \mathrm{mg} / \mathrm{L})$, anfoterecina $(2 \mathrm{mg} / \mathrm{L})$, suplementado com $10 \%$ de soro fetal bovino. A cepa de BoHV-1.2 SV-56/90 foi isolada de um surto de balanopostite em touros de uma central de inseminação artificial no estado do Rio Grande do Sul, Brasil (Weiblen et al. 1992). Esse vírus foi posteriormente submetido à caracterização antigênica e molecular, constatando-se tratar de vírus do subtipo 1.2 (D'Arce et al. 2002).

Animais, inoculação viral e administração de dexametasona (Dx). Quatro bezerras soronegativas para o BoHV-1, com idade entre 8 e 10 meses foram inoculadas e uma bezerra permaneceu como controle não inoculado. Os animais foram inoculados na vulva, vestíbulo e no terço posterior da vagina, com $3 \mathrm{~mL}$ de uma suspensão contendo $10^{8.1} \mathrm{TCID}_{50} / \mathrm{mL}$ do vírus, com auxílio de um suabe. A bezerra controle foi inoculada com o mesmo volume de MEM. Cinqüenta e cinco dias após a inoculação (p.i.), as bezerras inoculadas foram submetidas à administração de $D x(0,2 \mathrm{mg} / \mathrm{kg} / \mathrm{dia})$ por cinco dias consecutivos. Os animais inoculados e o controle foram submetidos à eutanásia no dia 91 p.i. (36 dias após a reativação, p.r.) para a coleta de tecidos. Todos os procedimentos de manipulação e experimentação dos animais foram realizados com a supervisão de um Médico Veterinário e de acordo com o Comitê Brasileiro de experimentação animal (COBEA, law \#6.638 of May 8, 1979). O experimento foi aprovado anteriormente pelo Comitê de Ética da UFSM (número de aprovação: 48/2006).

Monitoramento dos animais, coleta e processamento das amostras. As bezerras foram monitoradas clinicamente pelo exame genital e a aferição da temperatura retal durante 15 dias após a inoculação e 15 dias após a administração de Dx. Secreções vaginais foram coletadas com auxílio de suabes e acondicionadas em $1 \mathrm{~mL}$ de MEM, do dia zero (dia da inoculação) ao dia 14 p.i. e nos 5 dias que precederam a administração de Dx. Para avaliação da reativação da infecção latente, secreções vaginais foram coletadas durante 15 dias após a administração de Dx. No laboratório, os suabes foram fortemente agitados em um vortex e posteriormente centrifugados a uma rotação de $10.000 \mathrm{xg}$ por $3 \mathrm{~min}$. Para tentativas de isolamento viral, uma parte do sobrenadante dos suabes $(0,2 \mathrm{~mL})$ foi inoculado em monocamadas de células CRIB cultivadas em placas de poliestireno de 24 cavidades e submetido a três passagens de cinco dias cada para monitoramento do efeito citopático. A infectividade das secreções que foram positivas no isolamento viral foi posteriormente quantificada por titulação por diluição limitante, e os títulos virais foram expressos em $\log _{10}{ }^{T} C_{1} D_{50} /$ $\mathrm{mL}$. Amostras de sangue para a pesquisa de anticorpos antiBoHV-1 foram coletadas no dia da inoculação e nos dias $14 \mathrm{e}$ 28 pi; no dia da administração de Dx e 14 e 28 dias após. Para a detecção de anticorpos, as amostras de soro foram submetidas ao teste de soroneutralização (SN) de acordo com a técnica descrita por Lovato et al. (1995).

$\mathrm{Na}$ necropsia, foram coletados os gânglios sacrais e linfonodos regionais do trato genital dos animais inoculados e do animal controle para a pesquisa de DNA viral por PCR e para isolamento viral. Foram coletados os seguintes gânglios sacrais: genito-femoral (L3-L4); ciático (S1-S2); obturador (L4L6); pudendo (S2-S4); e retal caudal (S4-S5). Os linfonodos regionais coletados foram: supramamário, inguinal profundo, sacral, ilíaco médio e pré-femoral (Quadro 3). Tentativas de isolamento viral foram realizadas apenas dos tecidos que foram positivos no PCR. Para a pesquisa de vírus, aproximadamente $500 \mathrm{mg}$ de cada tecido foram maceradas e homogeneizadas em MEM na proporção de 10\% (peso/volume). A suspensão foi inoculada em monocamadas de células CRIB para monitoramento da replicação viral, como descrito para o isolamento viral a partir das secreções genitais.

Extração de DNA e PCR. Para a realização de PCR, amostras de tecidos (200-400 $\mathrm{mg}$ ) foram fragmentadas individualmente com o auxílio de lâminas de bisturi, e submetidas a extração de DNA utilizando o reagente DNAzol (Invitrogen, Carlsbad, CA, USA) de acordo com instruções do fabricante. Após a extração, o DNA foi solubilizado em $8 \mathrm{mM} \mathrm{NaOH}(0,15-0,20 \mathrm{ml})$ e estocado a $-20^{\circ} \mathrm{C}$ até o teste. A concentração de DNA foi determinada em um espectrofotômetro de UV a 260nm. 
O DNA viral foi detectado por um PCR-nested para uma região do gene da glicoproteína $\mathrm{B}(\mathrm{gB})$ do BoHV-1, descrito por Ros \& Belak (1999) e modificado por Mayer et al. (2006). A seqüência alvo $(444 \mathrm{pb})$ foi inicialmente amplificada com os primers externos \#1 (forward) 5'-CCAGTCCAGGCAACCGTCAC-3' (posição 57.338) e \#2 (reverse) 5'-CTCGAAAGCCGAGTACCTGCG-3' (posição 57.782). A segunda reação utilizou $2 \mu \mathrm{L}$ da primeira reação como molde e os primers internos \#3 (forward) 5'-GTGGTGGCCTTTGACCGCGAC-3' (posição 57.143) e \#4 (reverse) 5'-GCTCCGGCGAGTAGCTGG TGTG3' (posição 57.416). As reações de PCR foram realizadas em um volume final de $25 \mu \mathrm{L}$, utilizando $2 \mu \mathrm{L}$ do molde de DNA (aproximadamente $1 \mu \mathrm{g}$ do total de DNA), 100ng de cada primer, $1 \mathrm{mM} \mathrm{MgCl} 2,10 \mathrm{mM}$ de dNTPs, $10 \%$ DMSO, $1 \mathrm{x}$ tampão e 0,5 unidades de Taq polymerase (Invitrogen). As condições do PCR foram: denaturação inicial a $94^{\circ} \mathrm{C}$ por $10 \mathrm{~min}$ seguido de 40 ciclos de $94^{\circ} \mathrm{C}$ - 1 min (denaturação); $56^{\circ} \mathrm{C}-40$ seg (anelamento) e de $72^{\circ} \mathrm{C}$ - 40 seg (extensão); e uma extensão final de $72^{\circ} \mathrm{C}$ por $7 \mathrm{~min}$. Como controle positivo foi utilizado o DNA extraído do gânglio sacral de um touro inoculado pela via intraprepucial com o isolado SV-56/90 (Vogel et al. 2004). Como controle negativo foi utilizado o DNA extraído de um gânglio sacral do animal controle. A análise dos produtos foi realizada após eletroforese em gel de agarose a 1,5\% corado com brometo de etídio, e examinado sob luz UV.

\section{RESULTADOS}

Infecção aguda. O Quadro 1 apresenta um resumo dos achados virológicos observados durante a infecção aguda. Excreção viral em secreções genitais foi detectada entre os dias 1 e 10 p.i., com duração de 8-10 dias e títulos de até $10^{7.3} \mathrm{TCID}_{50} / \mathrm{mL}$. Os títulos máximos foram observados entre os dias 2 e 3 p.i. Todos os animais inoculados apresentaram títulos de anticorpos neutralizantes (4-32) no dia 28 p.i. O animal controle não excretou vírus nem soroconverteu durante a realização do experimento.

Nenhum dos animais inoculados apresentou aumento da temperatura corporal durante o período de monitoramento. As quatro bezerras inoculadas desenvolveram sinais moderados a severos de vulvovaginite. Os sinais foram inicialmente observados no dia 2 p.i., e eram caracterizados por congestão e edema da mucosa vulvovesti-

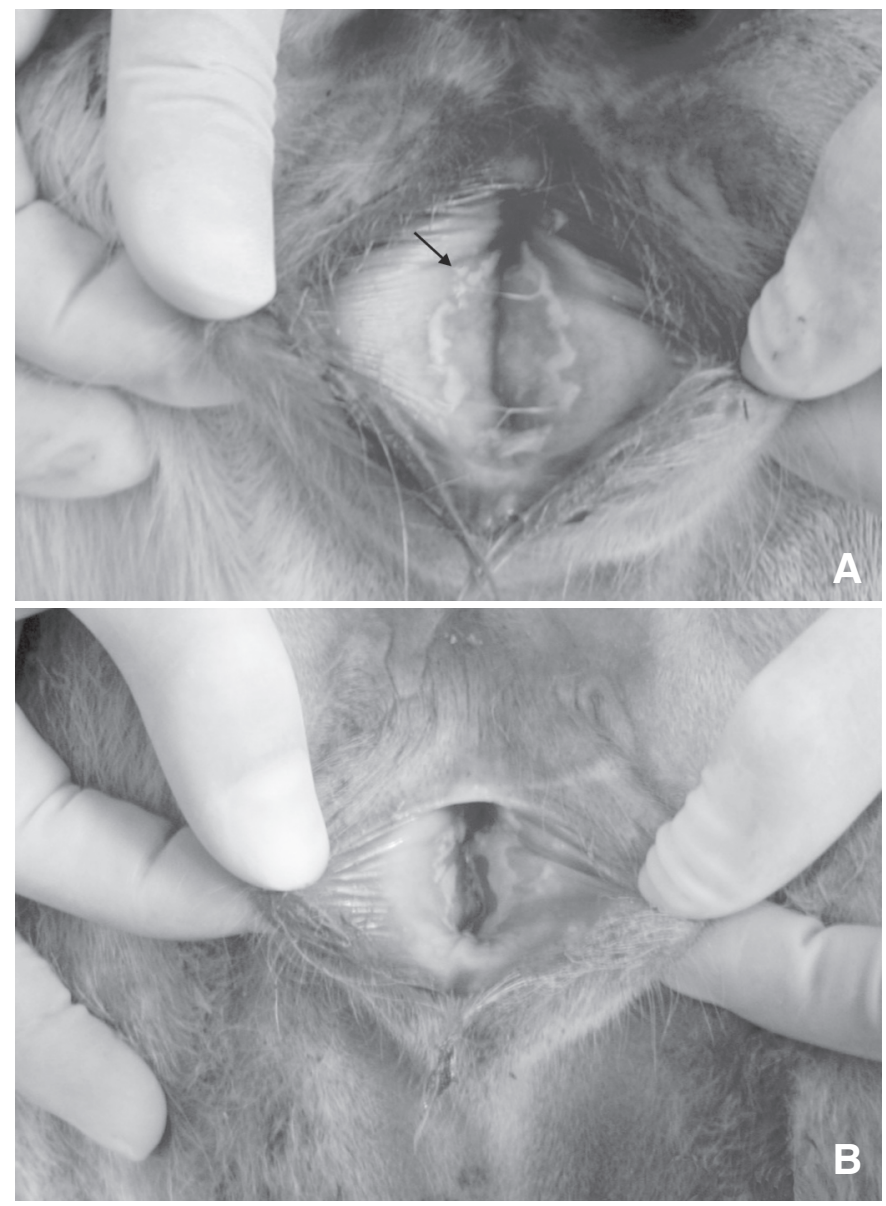

Fig.1. Região vulvovestibular de bezerras inoculadas com o BoHV-1.2, durante a infecção aguda. (A) Bezerra 09 (dia 6 p.i.): edema e congestão; presença de pequenas pústulas (seta) e secreção fibrinopurulenta. (B) Bezerra 122 (dia 6 p.i.): edema e congestão; secreção de coloração amarelada recobrindo as vesículas e pústulas remanescentes.

bular e da vagina posterior. No dia 3 p.i., os sinais se tornaram mais pronunciados e observou-se o aparecimento de pequenas vesículas (aprox. 1-2mm de diâmetro) na mucosa genital (Fig.1A). As vesículas aumentaram pro-

Quadro 1. Excreção viral em secreções genitais e título de anticorpos neutralizantes durante a infecção aguda, em bezerras inoculadas com o herpesvírus bovino tipo 1.2 (BoHV-1.2) no trato genital

\begin{tabular}{|c|c|c|c|c|c|c|c|c|c|c|c|c|c|}
\hline \multirow[t]{3}{*}{ Animal } & \multicolumn{11}{|c|}{ Excreção viral ${ }^{\mathrm{a}}$} & \multirow{2}{*}{\multicolumn{2}{|c|}{$\begin{array}{c}\text { Título de anticorpos } \\
\text { neutralizantes }{ }^{b} \\
\text { Dias }\end{array}$}} \\
\hline & \multicolumn{11}{|c|}{ Dias após inoculação (pi) } & & \\
\hline & 1 & 2 & 3 & 4 & 5 & 6 & 7 & 8 & 9 & 10 & $11-14$ & 0 & 28 \\
\hline 09 & 2.8 & 7.3 & 6.7 & 3.8 & 4.9 & 4.8 & 3.9 & 3.5 & 2.1 & $\mathrm{~d} \leq 1.8^{\mathrm{c}}$ & - & $<2$ & 16 \\
\hline 122 & $n t^{d}$ & 6.9 & 4.8 & 3.8 & 4.5 & 3.7 & 4.5 & $d \leq 1.8$ & 2.5 & - & - & $<2$ & 32 \\
\hline 124 & nt & 5.8 & 5.5 & 5.5 & 4.8 & 3.8 & 3.2 & $\mathrm{~d} \leq 1.8$ & $\mathrm{~d} \leq 1.8$ & - & - & $<2$ & 8 \\
\hline 125 & 5.6 & 5.8 & 3.8 & 4.9 & 2.9 & 3.3 & 2.9 & $\mathrm{~d} \leq 1.8$ & nt & - & - & $<2$ & 4 \\
\hline Controle & - & - & - & - & - & - & - & - & - & - & - & $<2$ & $<2$ \\
\hline
\end{tabular}

a Títulos virais em secreções vaginais expressos em $\log _{10} \mathrm{TCID}_{50} / \mathrm{mL}$.

b Títulos de anticorpos neutralizantes expressos como a recíproca de maior diluição do soro capaz de prevenir a produção de efeito citopático em cultivo celular.

c Infectividade detectada apenas no inóculo não diluído.

d Amostra não testada. 
Quadro 2. Excreção viral em secreções genitais e título de anticorpos neutralizantes após a
administração de dexametasona (Dx), em bezerras inoculadas com herpesvírus bovino tipo 1.2 (BoHV-1.2) no trato genital

\begin{tabular}{|c|c|c|c|c|c|c|c|c|c|c|c|c|c|}
\hline \multirow[t]{3}{*}{ Animal } & \multicolumn{11}{|c|}{ Excreção viral $^{a}$} & \multirow{2}{*}{\multicolumn{2}{|c|}{$\begin{array}{c}\text { Título de anticorpos } \\
\text { neutralizantes } \\
\text { Dia }(p D x)\end{array}$}} \\
\hline & \multicolumn{11}{|c|}{ Dias após a adminstração de Dx (pDx) } & & \\
\hline & $1-2$ & 3 & 4 & 5 & 6 & 7 & 8 & 9 & 10 & 11 & 12 & 0 & 28 \\
\hline 09 & - & $\mathrm{d} \leq 1.8$ & 2.6 & 2.9 & 3.1 & 4.3 & 3.6 & $n t^{\mathrm{C}}$ & $\mathrm{d} \leq 1.8$ & - & $\mathrm{d} \leq 1.8$ & 16 & 32 \\
\hline 122 & - & nt & $\mathrm{d} \leq 1.8^{\mathrm{d}}$ & $\mathrm{d} \leq 1.8$ & 2.8 & 3.3 & 1.8 & $\mathrm{~d} \leq 1.8$ & - & - & - & 32 & 128 \\
\hline 124 & - & - & - & $\mathrm{d} \leq 1.8$ & $\mathrm{~d} \leq 1.8$ & 3.5 & $\mathrm{~d} \leq 1.8$ & $\mathrm{~d} \leq 1.8$ & $\mathrm{~d} \leq 1.8$ & $\mathrm{~d} \leq 1.8$ & $\mathrm{~d} \leq 1.8$ & 4 & 32 \\
\hline 125 & - & $\mathrm{d} \leq 1.8$ & 3.1 & 2.8 & 3.3 & 3.8 & $\mathrm{~d} \leq 1.8$ & $\mathrm{~d} \leq 1.8$ & $\mathrm{~d} \leq 1.8$ & - & - & 4 & 16 \\
\hline Controle & - & - & - & - & - & - & - & - & - & - & - & $<2$ & $<2$ \\
\hline
\end{tabular}

a Títulos virais obtidos em secreções vaginais expressos em $\log _{10} \mathrm{TCID}_{50} / \mathrm{mL}$.

b Títulos de anticorpos neutralizantes expressos como a recíproca de menor diluição do soro capaz de prevenir a produção de efeito citopático em cultivo celular inoculado com o BoHV-1.

${ }^{c}$ Amostra não testada.

d Infectividade detectada apenas no inóculo não diluído.

gressivamente de diâmetro e deram lugar a pústulas, que eventualmente se tornaram coalescentes e recobertas por uma secreção amarelada. Durante esse período, houve o surgimento de novas vesículas. Observou-se um corrimento genital, que era inicialmente discreto e seromucoso (dias 2-4 p.i.), passando a abundante e mucopurulento (dias 5-8) (Fig.1B). A severidade das lesões aumentou progressivamente até os dias 5-8 p.i. e declinou a partir daí até o dia 10 p.i., quando apenas lesões residuais eram observadas. Durante o pico dos sinais clínicos, os animais hesitavam em se locomover, apresentavam a cauda erguida e deslocada lateralmente e urinavam com freqüência, em pequenos jatos.

Essas observações demonstram que o isolado SV56/ 90 - originalmente isolado de casos de balanopostite - é capaz de replicar eficientemente na mucosa genital de fêmeas e produzir vulvovaginite moderada a severa após infecção experimental.

Infecção latente. A pesquisa de vírus em secreções genitais coletadas nos cinco dias que precederam a administração de Dx não revelou a presença de infectividade. Após a administração de Dx, o vírus foi excretado nas secreções genitais de todas as bezerras inoculadas, a partir do dia 3 p.r., porém em títulos inferiores aos detectados durante a infecção aguda. A excreção viral persistiu até o dia 12 p.r. em dois animais (Quadro 2). Três bezerras apresentaram um aumento significativo (superior a 4x) nos títulos neutralizantes após a administração de Dx.

Uma observação até certo ponto surpreendente foi a recrudescência clínica, bem pronunciada, apresentada por todas as bezerras inoculadas durante a reativação. Edema vulvovaginal foi observado a partir do dia 2 p.r. e durou por até 8-10 dias. Em uma bezerra (125), o edema e a congestão foram inclusive mais pronunciados do que durante a infecção aguda, porém sem a presença de vesículas (Fig.2A). A recrudescência na bezerra 124 cursou com o desenvolvimento de vesículas e pústulas, que evoluíram para crostas. Neste animal, pequenas vesículas e pústulas foram observadas até o dia 14 p.r. (Fig.2B).

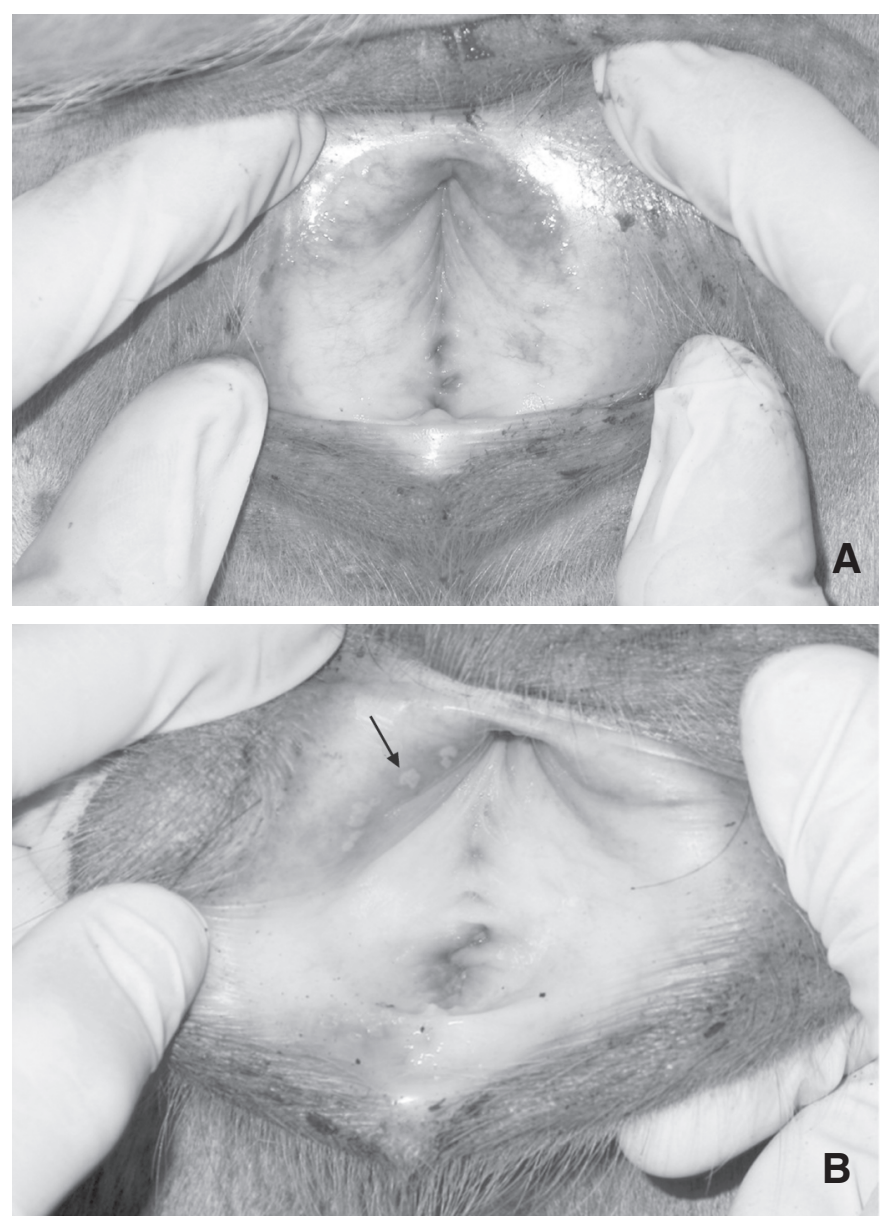

Fig.2. Região vulvovestibular de bezerras inoculadas com o BoHV-1.2, após a reativação induzida pela administração de dexametasona (Dx). (A) Bezerra 125 (dia 6 p.r.): edema e congestão. (B) Bezerra 124 (dia 7 p.r.): edema, congestão e pequenas pústulas (seta).

Em geral, a severidade dos sinais aumentou até os dias 5 e 9 p.r., regredindo progressivamente a partir de então. $O$ animal controle não apresentou qualquer alteração clínica durante o experimento. 
Quadro 3. Detecção de DNA do herpesvírus bovino tipo 1.2 (BoHV-1.2) por PCR em tecidos de bezerras inoculadas no trato genital, aos 91 dias pós-inoculação (36 dias pósreativação)

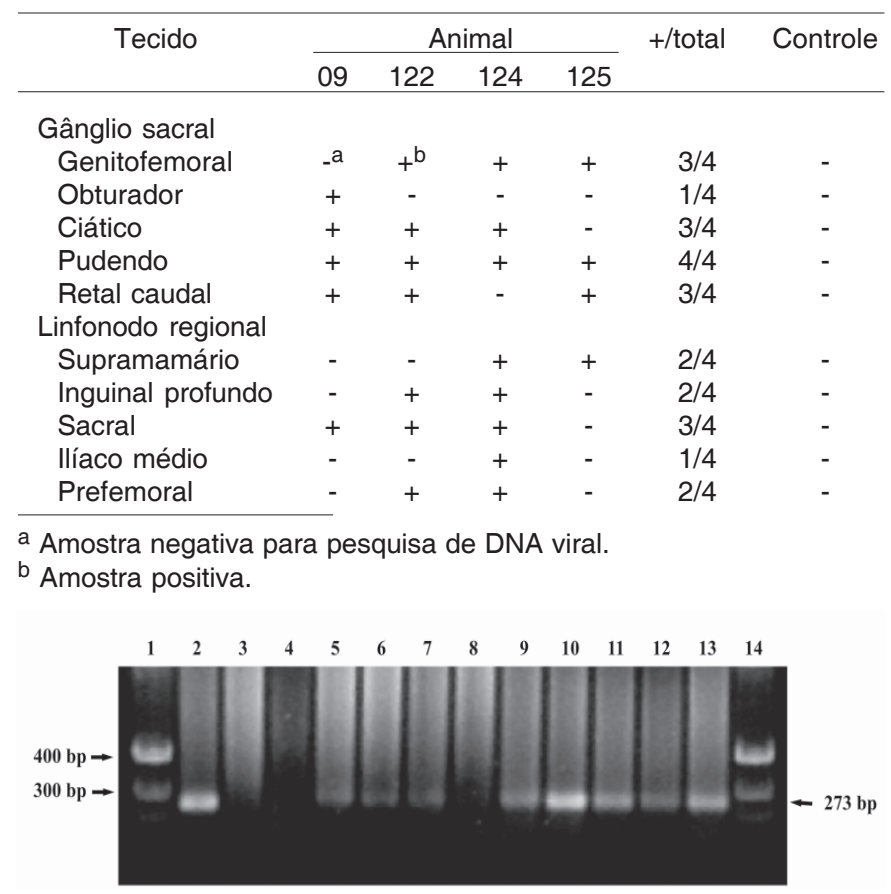

Fig.3. Especificidade do PCR para o gene da glicoproteína B utilizado para detectar a presença de DNA do BoHV-1.2 em tecidos de bezerras inoculadas experimentalmente. A Figura mostra um gel de agarose a 1,5\% corado com brometo de etídio. Colunas 1 e 14: marcador de peso molecular (ladder de 100pb). Coluna 2: controle positivo: DNA extraído do gânglio sacral de um touro latentemente infectado com o BoHV-1.2. Coluna 3: DNA extraído de um gânglio sacral de um bezerro não infectado. Colunas 4 a 13: DNA extraído de tecidos coletados do animal no 124 no dia 91 p.i. (36 p.r.); 4: gânglio obturador; 5: gânglio pudendo; 6: gânglio ciático; 7: gânglio genitofemoral; 8: gânglio retal caudal; 9: linfonodo supramamário; 10: linfonodo prefemoral; 11: linfonodo inguinal profundo; 12: linfonodo sacral; 13: linfonodo ilíaco médio. Os fragmentos de 300 e 400pb do ladder estão indicados no lado esquerdo; o tamanho dos produtos amplificados (273 bp) está indicado do lado direito.

Estes resultados indicam que a infecção latente estabelecida pelo isolado SV-56/90 em bezerras após infecção genital pode ser reativada pela administração de Dx, e que a reativação cursa com recrudescência clínica.

Detecção de DNA viral em tecidos. Os resultados da pesquisa de DNA viral latente nos gânglios sacrais e em linfonodos regionais coletados no dia 36 p.r. (91 dias p.i.) estão apresentados no Quadro 3. A Figura 3 apresenta os produtos de PCR amplificados dos tecidos da bezerra 124. O DNA viral foi detectado com mais freqüência no gânglio pudendo (4/4), seguido do genitofemoral, ciático, retal caudal (3/4) e obturador (1/4). Em todos os animais, o DNA viral foi também detectado em alguns linfonodos regionais, com diferentes freqüências. A especificidade da amplificação pode ser comprovada pela ausência de detecção de DNA nos tecidos do animal controle. Tentativas de isolamento viral a partir dos tecidos positivos no PCR resultaram negativas, o que caracteriza a infecção latente: presença de DNA viral na ausência de replicação e produção de progênie infecciosa.

\section{DISCUSSÃO}

O isolado SV-56/90 replicou com eficiência e produziu vulvovaginite clínica de intensidade moderada a severa em bezerras, após inoculação no trato genital. A infecção aguda foi seguida do estabelecimento de infecção latente, que pode ser reativada pela administração de Dx. A reativação induzida experimentalmente cursou com excreção viral, recrudescência clínica e soroconversão. $O$ DNA viral latente - sem presença de replicação produtiva - foi detectado por PCR em vários gânglios sacrais e em alguns linfonodos regionais no dia 36 p.r. Esses achados demonstram que o isolado SV-56/90 é virulento também para fêmeas e contribuem para o entendimento da patogenia da infecção genital pelo BoHV-1.2.

Os isolados de BoHV-1.2 associados com IPB provavelmente são os mesmos envolvidos na etiologia da IPV e, certamente, circulam entre machos e fêmeas indistintamente (Deas \& Johnston 1973, Kahrs 2001). Até o presente, não existem marcadores moleculares que permitam a distinção entre isolados de IPV e de IPB, mas pequenas diferenças genotípicas e fenotípicas podem existir entre as amostras isoladas desses quadros. Essas diferenças, se realmente existirem, provavelmente refletem a adaptação do vírus aos respectivos epitélios (dos tratos genitais feminino e masculino, respectivamente) (Muylkens et al. 2007). Não obstante, infecções naturais e experimentais indicam que amostras isoladas de IPB, ou do sêmen de touros com infecção subclínica, são capazes de produzir IPV e vice-versa (Saxegaard 1970, Deas \& Johnston 1973, Parsonson \& Snowdon 1975, Pritchard et al. 1997). Os resultados do presente estudo corroboram essas informações: a amostra SV-56/90 - isolada de um surto de IPB e capaz de reproduzir a doença clínica após infecção experimental em touros jovens - apresentou a mesma capacidade de replicação e virulência quando inoculada no trato genital de fêmeas. Essas propriedades fazem deste isolado um candidato adequado para estudos de patogenia da infecção genital em ambos os sexos e para testes de desafio à proteção vacinal.

Mesmo antes do reconhecimento do BoHV-1 como o agente etiológico do IPV/IPB, a persistência da infecção nos rebanhos e a ocorrência intermitente de casos clínicos de doença genital eram atribuídos a uma suposta imunidade de curta duração, a um agente até então desconhecido. Após a identificação do BoHV como agente etiológico da IPV/IPB, vários estudos relataram a persistência e reativação periódica da infecção em machos e fêmeas (Snowdon 1965, Sheffy \& Davies 1972, Dennet et al. 1976). Posteriormente, dois estudos clássicos demonstraram a presença do DNA latente do BoHV-1 nos gânglios trigêmeos 
e sacrais de bezerros e bezerras após a infecção intranasal e genital (Ackermann et al. 1982, Ackermann \& Wyler 1984). Recentemente, foi relatado um mapeamento detalhado da distribuição do DNA viral latente do BoHV-1.2 após inoculação pela via intraprepucial do SV-56/90 em touros jovens, no qual a infecção latente foi detectada em vários gânglios sacrais e em linfonodos regionais (Vogel et al. 2004). Um dos objetivos do presente experimento foi mapear a infecção latente nos gânglios sacrais e linfonodos regionais de fêmeas inoculadas com este isolado.

Os resultados deste mapeamento corroboram e complementam estudos realizados por Ackermann \& Wyler (1984). Esses autores detectaram o DNA latente do BoHV-1 por hibridização in situ (ISH) em 9 de 20 gânglios sacrais de duas bezerras inoculadas pela via intravaginal. No entanto, naquele estudo, a identidade dos gânglios sacrais envolvidos não foi especificada. Além disso, não foram investigados possíveis sítios adicionais de latência. No presente estudo, o DNA viral latente foi detectado em 14/20 gânglios sacrais e em 10/20 linfonodos regionais coletados no dia 91 p.i. (36 p.r.). Estes gânglios contêm os corpos celulares de neurônios sensoriais que inervam a genitália externa e interna (Pasquini \& Spurgeon 1989). A maior freqüência de detecção observada neste estudo em comparação ao anterior (Ackermann \& Wyler 1984) pode ser atribuída, em parte, a maior sensibilidade da PCR em relação à ISH. Também é possível que a distribuição do DNA latente tenha se expandido após a reativação induzida pela administração de Dx, como foi demonstrado na infecção pelo BoHV-5 em bezerros (Vogel et al. 2003) e em coelhos (Mayer et al. 2006). No presente estudo, a pesquisa de DNA viral latente foi realizada após um episódio de reativação experimental. Assim, é possível que alguns sítios de latência detectados no dia 36 p.r. não tenham sido colonizados imediatamente após a infecção primária e, sim, após a reativação induzida experimentalmente.

Em um estudo anterior (Vogel et al. 2004), após inoculação intraprepucial do isolado SV-56/90 em touros jovens, o DNA latente foi detectado por PCR em 16 de 19 gânglios sacrais, em 4 de 17 linfonodos regionais e também no plexo simpático de um animal. Apesar das diferenças de freqüência de detecção de DNA nos diferentes tecidos, ambos os estudos demonstraram que o BoHV1.2 estabelece infecção latente em vários gânglios sacrais, e também em linfonodos regionais após infecção genital.

Os resultados deste experimento corroboram e complementam estudos anteriores, demonstrando que o DNA latente do BoHV-1 pode ser encontrado em outros sítios, além dos gânglios nervosos, tanto após a infecção respiratória (Lovato et al. 2000, Winckler et al. 2000) quanto genital (Vogel et al. 2004). O DNA latente de outros alfaherpesvírus (vírus do herpes simplex humano, HSV; vírus da pseudoraiva, PRV) também tem sido detectado em sítios não-neurais (Cantin et al. 1994, Cheung 1995). No entanto, até o presente, o significado biológico da presença de DNA latente do BoHV-1 e de outros alfaherpes- vírus em sítios não neurais permanece não esclarecido, pois reativação viral a partir destes sítios ainda não foi demonstrada. É possível que a presença de DNA viral latente em sítios não neurais (especialmente em tecido linfóide) seja apenas um achado circunstancial, em conseqüência da replicação viral nestes tecidos durante a infecção aguda; ou devido ao direcionamento e localização de linfócitos infectados (Winckler et al. 2000). De qualquer forma, a presença de DNA latente em sítios não neurais é um achado interessante cujo significado biológico merece estudos adicionais.

A reativação da infecção latente se constitui em um meio eficiente de disseminação dos alfaherpesvírus na natureza (Rock 1994). Touros soropositivos para o BoHV1 excretam o vírus em secreções genitais durante episódios de reativação natural e/ou experimental (Bitsch 1973, Dennet et al. 1976, Vogel et al. 2004). Da mesma forma, o vírus pode ser detectado no trato genital de fêmeas, intermitentemente, por um longo tempo após a infecção aguda (Snowdon 1965) e após a reativação induzida por corticosteróides (Ackermann \& Wyler 1984). Embora os títulos e a duração da excreção viral durante a reativação sejam geralmente inferiores aos da infecção aguda, a reexcreção que ocorre durante a reativação parece ser suficiente para manter a circulação do vírus nos rebanhos. Neste estudo, o BoHV-1 foi excretado, durante a reativação, em títulos moderados (até $10^{4.3} \mathrm{TCID}_{50} / \mathrm{ml}$ ) nas secreções vaginais das bezerras por seis a oito dias após a administração de Dx. Embora experimentos para investigar a transmissão do vírus durante a reativação não tenham sido conduzidos, os níveis e duração da excreção viral são provavelmente suficientes para a ocorrência de transmissão a outros animais. A campo, condições de estresse, como manejo intensivo, impostas às fêmeas durante a temporada de reprodução, provavelmente contribuem para a reativação, excreção e transmissão viral.

A reativação da infecção latente por herpesvírus animais raramente é acompanhada de recrudescência clínica evidente (Pastoret \& Thiry 1985). No entanto, observações de campo já haviam relatado a ocorrência de episódios recorrentes de IPV por um longo tempo após a infecção aguda (Snowdon 1965). Da mesma forma, a reativação do BoHV-1.2 induzida por corticosteróides, em vacas com infecção latente, pode ser acompanhada por sinais leves de IPV (Dennet et al. 1976), embora esse não seja um achado consistente (Ackermann \& Wyler 1984). No presente estudo, a reativação induzida pela Dx resultou em IPV semelhante à observada durante a infecção aguda. Pequenas diferenças foram encontradas no número de vesículas (mais numerosas durante a infecção aguda), quantidade de secreção e intensidade do edema e congestão (mais severos durante a reativação). Por outro lado, esses achados confirmam observações anteriores, nas quais a recrudescência clínica, durante a reativação, foi detectada em touros inoculados com o isolado SV-56/90 (Vogel et al. 2004). A campo, é provável que a recrudescência clínica ocorra com mais freqüência 
do que anteriormente relatada, mas, por ser menos severa, passe despercebida na maioria das vezes. Por outro lado, a ocorrência esporádica de casos de IPV num rebanho por um longo período não necessariamente indica recrudescência da infecção latente. Uma parte destes novos casos pode ser decorrente da infecção primária em alguns animais, com vírus excretado pela reativação da infecção em animais portadores.

Concluindo, os resultados do presente experimento demonstram o fenótipo virulento do BoHV-1.2, amostra SV-56/90, para o trato genital de fêmeas e a capacidade desse isolado em estabelecer e reativar a infecção latente. Confirmando resultados anteriores, o DNA latente do BoHV-1.2 foi detectado em vários gânglios sacrais e também em alguns linfonodos regionais. O significado biológico desses sítios não-neurais de latência é incerto e atualmente está sendo investigado. Por outro lado, a reprodução consistente de doença genital após inoculação experimental de fêmeas soronegativas credencia o isolado SV-56/90 para estudos de patogenia e testes de desafio e proteção vacinal.

Agradecimentos.- A. Henzel e S. Arenhart são alunas do Programa de Pós-Graduação em Medicina Veterinária (PPGMV) da UFSM e bolsistas da CAPES; D.G. Diel foi aluno do PPGMV e bolsista do CNPq. E.F.Flores e R.Weiblen recebem bolsa de produtividade pelo CNPq. Agradecemos aos bolsistas e estagiários do Setor de Virologia da UFSM pelo auxílio durante o experimento.

\section{REFERÊNCIAS}

Ackermann M. \& Wyler R. 1984. The DNA of an IPV strain of bovid herpesvirus 1 in sacral ganglia during latency after intravaginal infection. Vet. Microbiol. 9:53-63.

Ackermann M., Peterhans E. \& Wyler R. 1982. DNA of bovine herpesvirus type 1 in the trigeminal ganglia of latently infected calves. Am. J. Vet. Res. 43:36-40.

Allan P.J., Dennet D.P. \& Johnson R.H. 1975. Studies on the effects of infectious bovine rhinotracheitis virus on reproduction in heifers. Aust. Vet. J. 51:370-373.

Bitsch V. 1973. Infectious bovine rhinotracheitis virus infection in bulls, with special reference to preputial infection. Appl. Microbiol. 26:337343.

Cantin E., Chen J., Gaidulis L., Valo Z. \& MacLaughlin-Taylor E. 1994. Detection of herpes simplex virus DNA sequences in human blood and bone marrow cells. J. Med. Virol. 42(3):279-286.

Cheung A.K. 1995. Investigation of pseudorabies virus DNA and RNA in trigeminal ganglia and tonsil tissues of latently infected swine. Am. J. Vet. Res. 56(1):45-50

D'Arce R.C.F., Almeida R.S., Silva T.C., Franco A.C., Spilki F., Roehe P.M. \& Arns C.W. 2002. Restriction endonuclease and monoclonal antibody analysis of Brazilian isolates of bovine herpesviruses types 1 and 5. Vet. Microbiol. 88:315-324.

Deas D.W. \& Johnston W.S. 1973. The isolation and transmission of the virus of infectious bovine rhinotracheitis/ infectious pustular vulvovaginitis. Vet. Rec. 92:636-639.

Dennet D.P., Barasa J.O. \& Johnson R.H. 1976. Infectious bovine rhinotracheitis virus: studies on the venereal carrier status in range cattle. Res. Vet. Sci. 20:77-83.

Edwards S., Newman R.H. \& White H. 1991. The virulence of British isolates of bovid herpesvirus 1 in relationship to viral genotype. Brit. Vet. J. 147:216-231.
Flores E.F. \& Donis R.O. 1995. Isolation of mutant MDBK cell line resistant to bovine viral diarrhea virus infection due to a block in viral entry. Virology 208:565-575.

Homan E.J. \& Easterday B.C. 1980. Isolation of bovine herpesvirus-1 from trigeminal ganglia of clinically normal cattle. Am. J. Vet. Res. 41(8):1212-1213.

Kahrs R.F. 2001. Infectious bovine rhinotracheitis and infectious pustular vulvovaginitis, p.159-170. In: (ed.), Viral diseases of cattle. $2^{\text {nd }}$ ed. Iowa State University Press, Ames. 370p.

Lovato L.T., Weiblen R., Tobias F.L. \& Moraes M.P. 1995. Herpesvírus bovino tipo 1 (BHV-1): inquérito soro-epidemiológico no rebanho leiteiro no estado do Rio Grande do Sul, Brasil. Ciência Rural 25(3):425430

Lovato L.T., Winkler M.T., Stone-Inman M., Doster A. \& Jones C. 2000. Detection of bovine herpesvirus Type 1 (BHV-1) viral DNA in peripheral blood mononuclear cells (PBMC). CRWAD, Proc. $81^{\text {st }}$ Annu. Meet., Nov. 12, 13 and 14, Chicago, lowa University Press, Ames. 129p.

Mayer S.V., Quadros V.L., Vogel F.S.F., Winkelmann E.R., Arenhart S., Weiblen R. \& Flores E.F. 2006. Dexamethasone-induced reactivation of bovine herpesvirus type 5 latent infection in experimentally infected rabbits results in a broader distribution of latent viral DNA in different regions of the brain. Braz J. Med. Biol. Res. 39:335-343.

Metzler A.E., Matile H., Gassmann U., Engels M. \& Wyler R. 1985. European isolates of bovine herpesvirus 1: A comparison of restriction endonuclease sites, polypeptides and reactivity with monoclonal antibodies. Arch. Virol. 85:57-69.

Miller J.M. \& Van Der Maaten M.J. 1984. Reproductive tract lesions in heifers after intrauterine inoculation with infectious bovine rhinotracheitis virus. Am. J. Vet. Res. 45(4):790-794.

Miller J.M., Whetstone C.A. \& Van Der Maaten M.J. 1991. Abortifacient property of bovine herpesvirus type 1 isolates that represent three subtypes determined by restriction endonuclease analysis of viral DNA. Am. J. Vet. Res. 52(3):458-461.

Muylkens B., Thiry J., Kirten P., Schynts F. \& Thiry E. 2007. Bovine herpesvirus 1 infection and bovine rhinotracheitis. Vet.Res. 38(2):181209.

Narita M., Inui S., Namba K. \& Shimizu Y. 1978. Neural changes in calves intravaginally inoculated with infectious bovine rhinotracheitis virus. J. Comp. Path. 88:381-386.

Parsonson I.M.\& Snowdon W.A. 1975. The effect of natural and artificial breeding using bulls infected with, or semen contaminated with, infectious bovine rhinotracheitis virus. Aust. Vet. J. 51:365-369.

Pasquini C. \& Spurgeon T. 1989. Anatomy of Domestic Animals. $6^{\text {th }}$ edition. SUDZ Publishing, Pilot Point, USA. 651p.

Pastoret P.P. \& Thiry E. 1985. Diagnosis and prophylaxis of infectious bovine rhinotracheitis: the role of virus latency. Comp. Immun. Microbiol. Infect. Dis. 8:35-42.

Pritchard G., Cook N. \& Banks M. 1997. Infectious pustular vulvovaginitis/ infectious pustular balanoposthitis in cattle. Vet. Rec. 31:587.

Rock D.L. 1994. Latent infection with bovine herpesvirus type 1. Sem. Virol. 5:233-240.

Roizman B. 1992. The family Herpesviridae: an update. Arch. Virol. 123(3/4):432-445.

Ros C. \& Belak V. 1999. Studies of genetic relationships between bovine, caprine, cervine, and rangiferine alphaherpesviruses and improved molecular methods for virus detection and identification. J. Clin. Microbiol. 37:1247-1253.

Saxegaard F. 1970. Infectious bovine rhinotracheitis/ infectious pustular vulvovaginitis (IBR/ IPV) virus infection of cattle with particular reference to genital infections. Vet. Bull. 40:605-611.

Sheffy B.E. \& Davies D.H. 1972. Reactivation of a bovine herpesvirus 
after corticosteroid treatment. Proc. Soc. Exp. Biol. Med. 140:974976.

Smith V.W., Coackler W. \& Maker D. 1980. Transmission of a genital isolate of bovine herpesvirus 1 to calves by the respiratory route. Aust. Vet. J. 56:302-304.

Snowdon W.A. 1965. The IBR-IPV virus: Reaction to infection and intermittent recovery of virus from experimentally infected cattle. Aust. Vet. J. 41:135-142.

Spilki F.R., Esteves P.A., Lima M., Franco A.C., Chiminazzo C., Flores E.F., Weiblen R., Driemeier D. \& Roehe P.M. 2004. Comparative pathogenicity of bovine herpesvirus 1 (BHV-1) subtypes 1 (BHV-1.1) and 2a (BHV-1.2a). Pesq. Vet. Bras. 24(1):43-49.

Van Oirschot J.T. 1995. Bovine herpesvirus 1 in semen of bulls and the risk of transmission: a brief review. Vet. Quarterly 17:29-33.

Van Oirschot J.T. 1999. Bovine viral vaccines, diagnosis, and eradication: past, present and future. Adv. Vet. Med. 41:197-216.

Vogel F.S.F., Caron L., Flores E.F., Weiblen R., Winkelman E.R., Mayer S.V. \& Bastos R.G. 2003. Distribution of bovine herpesvirus type 5
DNA in the central nervous system of latently, experimentally infected calves. J. Clin. Microbiol. 41(10):4512-4520.

Vogel F.S.F., Flores E.F., Weiblen R., Winkellman E.R., Moraes M.P. \& Bragança J.F.M. 2004. Intrapreputial infection of young bulls with bo-vine herpesvirus type 1.2. (BHV-1.2): acute balanoposthitis, latent infec-tion and detection of viral DNA in regional neural and nonneural tissues 50 days after experimental reactivation. Vet. Microbiol. 98:185-196.

Weiblen R., Kreutz L.C., Canabarro T.F., Schuch L.F. \& Rebelatto M.C. 1992. Isolation of bovine herpesvirus 1 from preputial swabs and semen of bulls with balanoposthitis. J. Vet. Diagn. Invest. 4:341-343.

Whetstone C.A., Miller J.M., Bortner D.M. \& Van Der Maaten M.J. 1989. Changes in the bovine herpesvirus 1 genome after reactivation from latency, and after superinfection in the host animal. Arch.Virol. 106(3/ 4):261-279.

Winkler M.T.C., Doster A. \& Jones C. 2000. Persistence and reactivation of bovine herpesvirus 1 in the tonsils of latently infected calves. J. Virol. 74(11):5337-5346. 